\title{
IMPROVEMENT OF FREE FAT SOFT CHEESE QUALITY USING EXOPOLYSACCHARIDE- PRODUCING LACTIC ACID BACTERIA AS STARTER MICROFLORA
}

Rasha A. Ghobashy ${ }^{1 *}$, El-Nawawy ${ }^{2}$ M.A., Hassanein ${ }^{1}$ A.M. and Aumara ${ }^{2}$ I.E.

1- Dairy Research Dept., Food Technology Research Institute, Agric. Research Center, Giza, Egypt.

2- Food Sci. Dept., Fac. Agric., Ain Shams Univ., P.O. Box 68, Hadayek Shobra11241, Cairo, Egypt

*Corresponding author: Rashaabdelsalam82@yahoo.com

Received 18 November, 2019

Accepted 12 January, 2020

\begin{abstract}
Free fat soft cheese was made from standardized buffalo's milk (control full fat $4.2 \%$ and $0.05 \%$ free fat milk). Milk were divided into eight portions, the first two treatments were made of full fat milk (control) without cheese starter (control), and the second was made of free fat milk without cheese starter (control). The other six treatments were made of free fat soft cheese with different starter cultures: $\mathrm{A} 1$ and $\mathrm{A} 2$ by using White Daily 82 and White Daily 42 (acid producing starter cultures). V1 and V2 treatments were made with mixed starter of acid-producing cultures (A1) and exopolysaccharide-producing lactic acid bacteria (YF-L811and YC-X11). V3 and V4 treatments were made with mixed starter of acid-producing cultures (A2) and exopolysaccharide-producing lactic acid bacteria (YF-L811 and YC-X11). Three replicates of full and free fat soft cheese were traditionally made and stored at $5 \pm 1^{\circ} \mathrm{C}$. Samples were analyzed when fresh and after $7,15,30,45,60,90$ and 120 days of storage, and examined for chemical, microbiological, rheological and organoleptic characteristics.

Results designated that, the use of exopolysaccharide-producing $L A B$ in $V 1$ treatment free fat soft cheese resulted in the highest soluble nitrogen / total nitrogen, soluble tyrosine and tryptophan contents, and the rate of accumulation of total volatile fatty acids compared, with all other cheese treatments. The highest lactic acid bacterial counts were detected in fresh V1 free fat soft cheese and V2. Lactic acid bacterial counts gradually decreased within 120 days of the storage. Yeast and mould counts were less than the standards within
\end{abstract}

first 60 days of the storage period. Total viable bacterial counts slightly increased in all cheese samples, as the storage period progressed. Hardness, cohesiveness, chewiness and adhesiveness properties were high in control full-fat, as compared with all other free fat cheese. Free fat soft cheeses in the presence of acid producing bacteria mixed with exopolysaccharide producing-lactic acid bacteria as starter culture could be recommended.

Keywords: Free fat soft cheese; Exopolysaccharide-producing lactic acid bacteria; Rheological properties; Storage period

\section{INTRODUCTION}

Recent medical research concerned on the importance of diet in the improvement of health. Milk products, include cheeses, especially those with reduced fat content, the good base for the development of such products. Starter culture microorganisms play a significant role in cheese making because of their helping acid production, proteolysis, and hence texture and flavor (taste and aroma) improvement (Banks 2004). The use of lactic acid bacterial ( $L A B)$ cultures underprovided in peptidase activity have also specified that peptidases, are complicated in the degradation of bitter peptides; these peptidase so influence the expansion of the organoleptic qualities of the milk product (Patel and Prajapati 2013; Ling Zhang et al 2015). The use of adjunct cultures has been quite promising in low-fat cheese manufacture and resulted in enhancement of cheese flavor. ie. Cheddar (Fenelon et al 2002), Feta (Michaelidou et al 2003a). Improvement of cheese sensory proper- 
ties, especially of aroma and taste (flavor), by using adjunct cultures, has mainly been related with development of proteolysis and with increased concentration of small peptides, chiefly of free amino acids in the final cheese product (Law, 2010). While, the physical characteristics of cheese, containing flavor (taste and aroma), depend on an amount of aspects, such as milk type. Milk composition, milk heat treatment, type and level of acidification, cheese composition, $\mathrm{pH}$ of the cheese, the content of calcium and other minerals, and the ripening conditions (Gutierrez et al 2013). In a Texture Profile Analysis (TPA), a cheese sample is compressed and decompressed double, simulating the chewing of product. The results found give different texture notes which provide a strong relationship with those obtained by sensorial methods and is one of the most joint tests for evaluating cheese texture (Gunasekaran and AK, 2003; Bourne, 2004). This work was done to improve the properties of soft free-fat cheeses that are required at the commercial and nutritional level without adding any other additives.

\section{MATERIAL AND METHODS}

\section{Materials}

\section{A. Ingredients}

Fresh buffalos' milk was obtained from the herd of the Faculty of Agriculture, Cairo University. The Chemical composition of cheese milk is shown in Table (1).

Table 1. Chemical composition of buffalos' milk used for making of soft cheese with different starter cultures

\begin{tabular}{|l|c|c|c|c|c|c|}
\hline & $\begin{array}{c}\text { T.S } \\
\%\end{array}$ & $\begin{array}{c}\text { Fat } \\
\%\end{array}$ & $\begin{array}{c}\text { T.P } \\
\%\end{array}$ & Lactose & Ash & Acidity \\
$\%$ & $\%$ \\
\hline Full fat & 13.86 & 4.2 & 4.74 & 4.4 & 0.52 & 0.17 \\
Free fat & 10.67 & 0.05 & 5.11 & 4.8 & 0.72 & 0.16 \\
\hline
\end{tabular}

T.P. Total protein

\section{B. Starter cultures}

LAB starter cultures were presented from Chr. Hansens Laboratory Denmark. These starter cultures are:

1- A1= Lactoccoccus lactis subsp. Lactis, Lactoccoccus lactis subsp. creamoris, Streptococcus thermophiles, Lactobacillus delbrueckii subsp. bulgaricus and Lactobacillus helveticus (White Daily 82).
2- $\mathrm{A} 2=$ Lactoccoccus lactis subsp. Lactis, Lactoccoccus lactis subsp. creamoris, Streptococcus thermophiles and Lactobacillus delbrueckii subsp. bulgaricus (White Daily 42).

3- V1= (White Daily 82) with Streptococcus thermophiles and Lactobacillus delbrueckii subsp. bulgaricus (YF-L811).

4- V2= (White Daily 82) with Streptococcus thermophiles and Lactobacillus delbrueckii subsp. bulgaricus (YC-X11).

$5-\mathrm{V} 3=($ White Daily 42) with (YF-L811).

$6-\mathrm{V} 4=($ White Daily 42) with (YC-X11).

\section{Methods}

\subsection{Cheese making}

Soft cheese was prepared traditionally according to the method described by Abou-Donia (1986) from fresh standardized buffalo's milk (for control and $0.05 \%$ fat for free fat cheeses). Milk was heated to $72^{\circ} \mathrm{C} / 15 \mathrm{sec}$., cooled to $40^{\circ} \mathrm{C}$. Than inoculated with $2 \%$ different starter cultures. sodium-chloride $(\mathrm{NaCl}) 5 \%, \mathrm{CaCl}_{2} 0.02 \%$ and rennet powder $5 \mathrm{~g} / 100 \mathrm{~kg}$ milk were added. Samples were incubated at $40^{\circ} \mathrm{C}$ untill complete coagulation. Curd was transferred into cloth-lined wooden frames for the drainage of whey, which took about $8 \mathrm{hrs}$. Pressing was practiced by using suitable weight for $16 \mathrm{hrs}$. Cheese was then cut, weighed and stored for 120 days at $5^{\circ} \mathrm{C}$. Cheese sample were then examined for their physicochemical, microbiological and rheological properties, as well as their sensory evaluation. Examination of the above properties was carried when fresh, and after $7,15,21,30,60,90,120$ days of storage.

\subsection{Physicochemical Properties}

All cheese was analyzed for the total nitrogen (TN) and soluble nitrogen (SN) contents by micro kjeldahl method, as described by AOAC (2012). Total solid content of cheese was determined by Gravimetric method, as described in IS 123331997. Moisture content and titratable acidity were determined as described in ling (1963). The soluble tyrosine and tryptophan contents of cheese samples were determined according to Vakaleris and Price (1959). pH values was measured using a digital $3510 \mathrm{pH}$ meter. Total volatile fatty acids (TVFA) were determined as described by Kosikowski (1966). Salt content was estimated as described by Marshall (2004). Ash content was detected as in AOAC (2012). 

producing lactic acid bacteria as starter microflora

\section{Rheological properties}

Rheological parameters were assessed using (FTC, FOOD TECHNOLOGY CORPORATION STERLING, VIRGINIA, USA www.foodtechcorp.com). Calculation described by Bourne (2003) to obtain the texture profile parameters (Hardness, Adhesiveness, Springiness, Chewiness and Gumminess)

\subsection{Microbiological Analysis}

Total Viable mesophilic bacterial count (TVBC) was determined using plate count agar according to Houghtby et al (1992). The plates were incubated at $32^{\circ} \mathrm{C}$ for $48 \mathrm{~h}$. Lactic acid bacterial count (LABC) was determined using MRS agar mentioned in De Man et al (1960). The plates were incubated at $32^{\circ} \mathrm{C}$ for $48 \mathrm{hrs}$. Psychrophilic bacterial count was determined using plate count agar according to Houghtby et al (1992). The plates were incubated at $10 \pm 2^{\circ} \mathrm{C}$ for $48 \mathrm{~h}$. Yeasts and Molds were enumerated according to Marshall (1992) using oxytetracycline glucose yeast extract agar. The plates were aerobically incubated at $25^{\circ} \mathrm{C}$ for 5 days.

\subsection{Sensory evaluation}

Soft cheese samples were organoleptically scored flavor (50 points), body and texture (40 points) and appearance (10 points), according to the score card suggested by Bodyfelt et al (1988). Samples were judged by the staff members of the Dairy Science Department, Agriculture Research Center.
2.5. Statistical Analysis: Statistical analysis was performed according SAS (2009), using General Linear Model (GLM) with main effect of treatments. Duncan's multiple range was used to separate among of three replicates at $\mathrm{p}=0.05$.

\section{RESULTS AND DISCUSSION}

(A) Chemical analysis

\section{(1) Dry matter content (\%DM)}

Table (2) shows the DM content (\%) of full and free fat soft cheese samples along the storage period for 120 days at $5 \pm 1^{\circ} \mathrm{C}$. DM content of fresh soft cheese samples ranged from 40.05 to $30.16 \%$ (in control full fat and control free fat soft cheese samples, respectively). DM content of all soft cheese treatments significantly increased as the storage period progressed. In addition, there are significant differences between fresh and stored free fat soft cheese samples made with starter culture. A1 had the highest DM content of $32.52 \%$, as compared with all other free fat soft cheese samples. On the contrary, DM content of free fat soft cheese made with V4was the lowest of $30.40 \%$, when fresh and throughout the storage. This might be due to the high ability of $\mathrm{A} 1$ starter culture to produce exopolysaccharides that hold moisture. Therefore, exopolysaccharides could be a good replacer of cheese fat. These differences in moisture content among the full-fat cheese and, partially skimmed milk cheeses might be attributed to their nitrogen (protein) content: i.e. a greater water-binding capacity of the cheese matrix may contribute to increase protein content of low-fat cheeses (Romeih et al 2002).

Table 2. DM content (\%) of free fat soft cheese along storage period for 120 days at $5 \pm 1^{\circ} \mathrm{C}$

\begin{tabular}{|c|c|c|c|c|c|c|c|c|c|}
\hline \multirow{2}{*}{ Treatments } & \multicolumn{7}{|c|}{ Storage period (days) } & \multirow{2}{*}{ TRT } \\
\cline { 2 - 9 } & $\mathbf{0}$ & $\mathbf{7}$ & $\mathbf{1 5}$ & $\mathbf{2 1}$ & $\mathbf{3 0}$ & $\mathbf{6 0}$ & $\mathbf{9 0}$ & $\mathbf{1 2 0}$ & DM \\
\cline { 2 - 9 } & \multicolumn{7}{|c|}{ TR } \\
Full fat C & $40.05^{\mathrm{Ah}}$ & $40.43^{\mathrm{Ag}}$ & $40.77^{\mathrm{Af}}$ & $41.25^{\mathrm{Ae}}$ & $41.78^{\mathrm{Ad}}$ & $42.54^{\mathrm{Ac}}$ & $43.20^{\mathrm{Ab}}$ & $44.00^{\mathrm{Aa}}$ & 41.75 \\
Free fat C & $30.16^{\mathrm{Eh}}$ & $31.30^{\mathrm{Eg}}$ & $32.53^{\mathrm{Ff}}$ & $33.88^{\mathrm{Ee}}$ & $35.28^{\mathrm{Ed}}$ & $36.37^{\mathrm{Fc}}$ & $37.24^{\mathrm{Fb}}$ & $38.23^{\mathrm{Ea}}$ & 34.37 \\
A1 & $32.52^{\mathrm{Bh}}$ & $34.12^{\mathrm{Bg}}$ & $35.66^{\mathrm{Bf}}$ & $37.26^{\mathrm{Be}}$ & $38.58^{\mathrm{Bd}}$ & $39.45^{\mathrm{Bc}}$ & $40.57^{\mathrm{Bb}}$ & $41.47^{\mathrm{Ba}}$ & 37.45 \\
A2 & $32.07^{\mathrm{Ch}}$ & $33.62^{\mathrm{Cg}}$ & $35.11^{\mathrm{Cf}}$ & $36.77^{\mathrm{Ce}}$ & $37.92^{\mathrm{Cd}}$ & $39.03^{\mathrm{Cc}}$ & $40.12^{\mathrm{Cb}}$ & $40.84^{\mathrm{Ca}}$ & 36.94 \\
V1 & $31.76^{\mathrm{Ch}}$ & $33.24^{\mathrm{Cg}}$ & $34.71^{\mathrm{Df}}$ & $36.19^{\mathrm{Ce}}$ & $37.43^{\mathrm{Cd}}$ & $38.54^{\mathrm{Dc}}$ & $39.69^{\mathrm{Db}}$ & $40.44^{\mathrm{Ca}}$ & 36.50 \\
V2 & $31.31^{\mathrm{Dh}}$ & $32.75^{\mathrm{Dg}}$ & $34.15^{\mathrm{Df}}$ & $35.46^{\mathrm{De}}$ & $36.83^{\mathrm{Dd}}$ & $37.95^{\mathrm{Dc}}$ & $39.09^{\mathrm{Db}}$ & $39.85^{\mathrm{Da}}$ & 35.92 \\
V3 & $30.87^{\mathrm{Dh}}$ & $32.14^{\mathrm{Dg}}$ & $33.54^{\mathrm{Ef}}$ & $35.03^{\mathrm{De}}$ & $36.35^{\mathrm{Dd}}$ & $37.45^{\mathrm{Ec}}$ & $38.57^{\mathrm{Eb}}$ & $39.53^{\mathrm{Da}}$ & 35.44 \\
V4 & $30.40^{\mathrm{Eh}}$ & $31.70^{\mathrm{Eg}}$ & $33.04^{\mathrm{Ef}}$ & $34.39^{\mathrm{Ee}}$ & $35.69^{\mathrm{Ed}}$ & $36.87^{\mathrm{Ec}}$ & $37.78^{\mathrm{Eb}}$ & $38.85^{\mathrm{Ea}}$ & 34.84 \\
\hline
\end{tabular}

Full fat C (Full fat control)

Free fat $\mathrm{C}$ (Free fat control) 


\section{(1) Titratable acidity (\%TA) and pH value}

Results of titratable acidity and $\mathrm{pH}$ values are presented in Table (3). Titratable acidity significantly increased, while there are significant decrease in $\mathrm{pH}$ values as the storage period progressed. Generally, free fat soft cheese samples made with starter culture $A 1$, followed by $A 2$ had the highest titratable acidity (\%TA) and the lowest $\mathrm{pH}$ values. The least significant titratable acidity (TA\%) and the highest $\mathrm{pH}$ values were recorded in the fresh control full fat and free fat soft cheese control. Significant differences were obtained among all treatments, which could be attributed to the presence of the starter culture, which came in agreement with Fenelon and Guinee (2000); Romeih et al (2002) and Abou Ayana and Amal, (2015) and Ling Zhang et al (2015).

\section{(1) Salt in water phase (SWP \%) and Ash/DM contents (\%)}

Results presented in Table (4) show Ash/DM (\%) of free fat soft cheese during the storage period for 120 days at $5 \pm 1^{\circ} \mathrm{C}$. Salt in water phase and Ash/DM contents of all soft cheese samples increased gradually by increasing of the storage period. This increase could be due to the gradual increase in DM and titratable acidity.

SWP and Ash/DM contents of free fat soft cheese made by $\mathrm{A} 1$ starter culture were significantly higher than all of the other examined samples. These results are in agreement with those reported by Badawi and Kebary (1998); Abou Ayana and Amal (2015). The results could be attributed to the reduction in the moisture content up to the end of the storage period.

In treatment A1 (11.67\%). Whatever, the least Ash/DM contents were in control fresh full-fat soft cheese (9.19\%).Ash/DM contents gradually increased along the storage at the end of storage period (120 days), Ash/DM content reached to $12.33-10.49 \%$ in treatment A1 and control full-fat, respectively. The highest (TRT) were recorded in treatment $A 1$, followed by treatment $A 2$, While, The least TRT was detected in control full fat.

SWP contents were higher in treatment $A 1$ $(5.33 \%)$. While, the least SWP contents were in control fresh free fat soft cheese $(4.30 \%)$. SWP contents gradually increased along the storage till the end of storage (120 days). These results agree with those of Kebary et al (2002). SWP content reached to (8.37-6.64\%) for treatment $A 1$ and free fat soft cheese respectively.
(2) Total Nitrogen / Dry mater, (TN/DM) and Soluble Nitrogen / Total Nitrogen (SN/TN) contents

TN/DM content of all cheese treatments are tabulated in Table (5). TN/DM contents were high in treatment $A 1$ (7.32\%). The least TN/DM contents were in the control fresh full-fat soft cheese (5.04\%). TN/DM contents gradually increased along the storage period at (60 days), followed by gradual decrease throughout the storage period until the end of storage period (120days), TN/DM contents reached to $6.16-4.86 \%$ in treatment A1and control full-fat. The highest content of (TRT) was recorded in treatment $A 1$, followed by treatment A2, whereas, the lowest TRT was observed in control full-fat. Proteolysis is the most multifaceted and, in most varieties, the most significant of the primary biochemical events that happen in most cheeses throughout ripening. Results obtained came in agreement with those reported by Fenelon and Guinee (2000), and Romeih et al (2002). Thermal- and freeze-shocked cells of selected $L b$. helveticus cultures increased proteolysis of cheese when added as an adjunct to the traditional lactic strain. Kim (1989).

Changes in soluble nitrogen and SN/TN contents are presented In Table (5). As it was expected, soluble nitrogen values continuously increased in all cheese throughout storage for 120days. Treatment V1 contained higher SN\% than control. Compositional effects (moisture and salt) might alter activity of rennet and/or cultures or non-starter proteolytic enzymes. Comparable observation had reported by Romeih et al (2002).

\section{(3) Soluble tryptophan $(\mathrm{mg} / 100 \mathrm{~g})$ and Tyrosine (mg/100g)}

Determination of these components is another index of the proteolysis being occurred in cheese during ripening. Data obtained concerning of these amino acids are recorded in Table (6). Soluble tryptophan content was higher in treatment V1 $(49.50 \mathrm{mg} / 100 \mathrm{~g})$. The lowest soluble content of tryptophan was $39.37 \mathrm{mg} / 100 \mathrm{~g}$ in control fresh fullfat soft cheese. Soluble tryptophan sharply increased along the storage at the end of storage period (120 days), soluble tryptophan reached 80.20 - $53.30 \mathrm{mg} / 100 \mathrm{~g}$ in treatment V1free fat soft cheese and control full-fat soft cheese, respectively. The highest (TRT) was recorded in treatment V1free fat soft cheese, followed by treatment V2 free fat soft cheese, while, the least TRT control full-fat. 
Table 3. Titratable acidity (\%TA) and $\mathrm{pH}$ values of free fat soft cheese along storage period for 120 days at $5 \pm 1^{\circ} \mathrm{C}$.

\begin{tabular}{|c|c|c|c|c|c|c|c|c|c|}
\hline \multirow{3}{*}{ Treatments } & \multicolumn{8}{|c|}{ Storage period (days) } & \multirow{3}{*}{ TRT } \\
\hline & 0 & 7 & 15 & 21 & 30 & 60 & 90 & 120 & \\
\hline & \multicolumn{8}{|c|}{ (Titratable acidity \%) } & \\
\hline Full fat $\mathrm{C}$ & $0.23^{\mathrm{Gh}}$ & $0.31^{\mathrm{Gg}}$ & $0.39^{\mathrm{Hf}}$ & $0.49^{G e}$ & $0.55^{\mathrm{Gd}}$ & $0.6^{\mathrm{Gc}}$ & $0.64^{\mathrm{Gb}}$ & $0.69^{G a}$ & 0.49 \\
\hline Free fat $\mathrm{C}$ & $0.20^{\mathrm{Gh}}$ & $0.29 \mathrm{Hg}$ & $0.38^{\mathrm{Hf}}$ & $0.47^{\mathrm{Ge}}$ & $0.53^{\mathrm{Gd}}$ & $0.57^{\mathrm{Gc}}$ & $0.60^{\mathrm{Gb}}$ & $0.65^{\mathrm{Ga}}$ & 0.46 \\
\hline A1 & $0.73^{\mathrm{ABh}}$ & $1.29^{\mathrm{Ag}}$ & $1.53^{\mathrm{Af}}$ & $1.72^{\mathrm{ABe}}$ & $1.90^{\mathrm{Ad}}$ & $2.04^{\mathrm{Ac}}$ & $2.16^{\mathrm{Ab}}$ & $2.28^{\mathrm{Aa}}$ & 1.71 \\
\hline $\mathbf{A 2}$ & $0.69^{\mathrm{Bh}}$ & $1.17^{\mathrm{Bg}}$ & $1.43^{\mathrm{BCf}}$ & $1.62^{\mathrm{Ce}}$ & $1.79^{\mathrm{Bd}}$ & $1.95^{\mathrm{BCc}}$ & $2.06^{\mathrm{Bb}}$ & $2.18^{\mathrm{Ba}}$ & 1.61 \\
\hline V1 & $0.64^{\mathrm{CDh}}$ & $1.07^{\mathrm{Cg}}$ & $1.33^{\mathrm{Df}}$ & $1.53^{\mathrm{De}}$ & $1.70^{\mathrm{Cd}}$ & $1.83^{\mathrm{Dc}}$ & $1.95^{\mathrm{Cb}}$ & $2.05^{\mathrm{Ca}}$ & 1.51 \\
\hline V2 & $0.59^{\mathrm{EFh}}$ & $0.99^{\mathrm{Dg}}$ & $1.24^{\mathrm{EFf}}$ & $1.44^{\mathrm{Ee}}$ & $1.61^{\mathrm{Dd}}$ & $1.74^{\mathrm{Ec}}$ & $1.86^{\mathrm{Db}}$ & $1.97^{\mathrm{Da}}$ & 1.43 \\
\hline V3 & $0.56^{\mathrm{Fh}}$ & $0.90^{\mathrm{Eg}}$ & $1.15^{\mathrm{Gf}}$ & $1.34 \mathrm{Fe}$ & $1.50^{\mathrm{Ed}}$ & $1.63^{\mathrm{Fc}}$ & $1.74^{\mathrm{Eb}}$ & $1.86^{\mathrm{Ea}}$ & 1.34 \\
\hline V4 & $0.52^{\mathrm{Gh}}$ & $0.83^{F g}$ & $1.07^{\mathrm{Hf}}$ & $1.26 \mathrm{Ge}$ & $1.41^{\mathrm{Fd}}$ & $1.54 \mathrm{Gc}$ & $1.65^{\mathrm{Fb}}$ & $1.74 \mathrm{Fa}$ & 1.25 \\
\hline \multicolumn{10}{|c|}{$\mathrm{pH}$} \\
\hline Full fat C & $6.30^{\mathrm{Aa}}$ & $6.09^{\mathrm{Ab}}$ & $5.98^{\mathrm{Ac}}$ & $5.79^{A d}$ & $5.68^{\mathrm{Ae}}$ & $5.56^{\mathrm{Af}}$ & $5.39^{\mathrm{Ag}}$ & $5.28^{\mathrm{Ah}}$ & 5.76 \\
\hline Free fat C & $6.36^{\mathrm{Aa}}$ & $6.18^{\mathrm{Ab}}$ & $6.02^{\mathrm{Ac}}$ & $5.82^{\mathrm{Ad}}$ & $5.70^{\mathrm{Ae}}$ & $5.58^{\mathrm{Af}}$ & $5.44^{\mathrm{Ag}}$ & $5.33^{\mathrm{Ah}}$ & 5.80 \\
\hline A1 & $5.20^{\mathrm{Ga}}$ & $4.72^{\mathrm{Gb}}$ & $4.46^{\mathrm{Gc}}$ & $4.25^{\mathrm{Gd}}$ & $4.08 \mathrm{Ge}$ & $3.96^{\mathrm{Gf}}$ & $3.85^{\mathrm{Gg}}$ & $3.76^{\mathrm{Gh}}$ & 4.29 \\
\hline A2 & $5.32^{\mathrm{Fa}}$ & $4.89^{\mathrm{Fb}}$ & $4.61^{\mathrm{Fc}}$ & $4.42^{\mathrm{Fd}}$ & $4.26 \mathrm{Fe}$ & $4.12^{\mathrm{Ff}}$ & $4.04 \mathrm{Fg}$ & $3.96^{\mathrm{Fh}}$ & 4.45 \\
\hline V1 & $5.45^{\mathrm{Ea}}$ & $5.13^{\mathrm{Eb}}$ & $4.88^{\mathrm{Ec}}$ & $4.66^{\mathrm{Ed}}$ & $4.50^{\mathrm{Ee}}$ & $4.32^{\mathrm{Ef}}$ & $4.21^{\mathrm{Eg}}$ & $4.13^{\mathrm{Eh}}$ & 4.66 \\
\hline V2 & $5.60^{\mathrm{Da}}$ & $5.31^{\mathrm{Db}}$ & $5.11^{\mathrm{Dc}}$ & $4.88^{\mathrm{Dd}}$ & $4.73^{\mathrm{De}}$ & $4.56^{\mathrm{Df}}$ & $4.40^{\mathrm{Dg}}$ & $4.34^{\mathrm{Dh}}$ & 4.87 \\
\hline V3 & $5.69 \mathrm{Ca}$ & $5.49^{\mathrm{Cb}}$ & $5.26^{\mathrm{Cc}}$ & $5.02^{\mathrm{Cd}}$ & $4.84^{\mathrm{Ce}}$ & $4.72^{\mathrm{Cf}}$ & $4.56^{\mathrm{Cg}}$ & $4.48^{\mathrm{Ch}}$ & 5.01 \\
\hline V4 & $5.83^{\mathrm{Ba}}$ & $5.65^{\mathrm{Bb}}$ & $5.41^{\mathrm{Bc}}$ & $5.223^{\mathrm{Bd}}$ & $5.01^{\mathrm{Be}}$ & $4.88^{\mathrm{Bf}}$ & $4.74^{\mathrm{Bg}}$ & $4.65^{\mathrm{Bh}}$ & 5.17 \\
\hline
\end{tabular}

Table 4. SWP (\%) and Ash/DM content (\%) of free fat soft cheese along storage period for 120 days at $5 \pm 1^{\circ} \mathrm{C}$

\begin{tabular}{|c|c|c|c|c|c|c|c|c|c|}
\hline \multirow{3}{*}{ Treatments } & \multicolumn{8}{|c|}{ Storage period (days) } & \multirow{3}{*}{ TRT } \\
\hline & 0 & 7 & 15 & 21 & 30 & 60 & 90 & 120 & \\
\hline & \multicolumn{8}{|c|}{ SWP\% } & \\
\hline Full fat C & $5.00^{\mathrm{Dh}}$ & $5.37^{\mathrm{Cg}}$ & $5.74^{\mathrm{Cf}}$ & $6.13^{\mathrm{Ce}}$ & $6.53^{\mathrm{Cd}}$ & $6.94^{\mathrm{Cc}}$ & $7.38^{\mathrm{Cb}}$ & $7.83^{\mathrm{Ca}}$ & 6.36 \\
\hline Free fat $\mathrm{C}$ & $4.30^{\mathrm{Fh}}$ & $4.51 \mathrm{Fg}$ & $4.74^{\mathrm{Ff}}$ & $4.99 \mathrm{Fe}$ & $5.41^{\mathrm{Fd}}$ & $5.81^{\mathrm{Fc}}$ & $6.21^{\mathrm{Fb}}$ & $6.64 \mathrm{Fa}$ & 5.33 \\
\hline A1 & $5.33^{\mathrm{ABh}}$ & $5.62^{\mathrm{Ag}}$ & $6.06^{\mathrm{Af}}$ & $6.53^{\mathrm{Ae}}$ & $7.00^{\mathrm{Ad}}$ & $7.43^{\mathrm{Ac}}$ & $7.91^{\mathrm{Ab}}$ & $8.37^{\mathrm{Aa}}$ & 6.78 \\
\hline A2 & $5.15^{\mathrm{Ch}}$ & $5.42^{\mathrm{Bg}}$ & $5.86^{\mathrm{Bf}}$ & $6.33^{\mathrm{Be}}$ & $6.77^{\mathrm{Bd}}$ & $7.05^{\mathrm{Bc}}$ & $7.68^{\mathrm{Bb}}$ & $8.11^{\mathrm{Ba}}$ & 6.56 \\
\hline V1 & $4.98^{\mathrm{Dh}}$ & $5.24^{\mathrm{Dg}}$ & $5.67^{\mathrm{Df}}$ & $5.96^{\mathrm{De}}$ & $6.55^{\mathrm{Cd}}$ & $7.00^{\mathrm{Cc}}$ & $7.46^{\mathrm{Cb}}$ & $7.89 \mathrm{Ca}$ & 6.34 \\
\hline V2 & $4.80^{\mathrm{Eh}}$ & $5.06^{\mathrm{Eg}}$ & $5.32^{\mathrm{Ef}}$ & $5.73^{\mathrm{Ee}}$ & $6.17^{\mathrm{Dd}}$ & $6.61^{\mathrm{Dc}}$ & $7.06^{\mathrm{Db}}$ & $7.48^{\mathrm{Da}}$ & 6.03 \\
\hline V3 & 4.63Eh & $4.86^{\mathrm{Eg}}$ & $5.12^{\mathrm{Ef}}$ & $5.54 \mathrm{Ee}$ & $5.97 \mathrm{Ed}$ & $6.39 \mathrm{Ec}$ & $6.84^{\mathrm{Eb}}$ & $7.11 \mathrm{Ea}$ & 5.81 \\
\hline \multirow[t]{2}{*}{ V4 } & $4.45^{\mathrm{Fh}}$ & $4.69 \mathrm{Fg}$ & $4.93^{\mathrm{Ff}}$ & $5.18^{\mathrm{Fe}}$ & $5.60^{\mathrm{Ed}}$ & $6.02^{\mathrm{Fc}}$ & $6.43^{\mathrm{Eb}}$ & $6.87^{\mathrm{Fa}}$ & 5.52 \\
\hline & \multicolumn{8}{|c|}{ Ash/DM\% } & \\
\hline Full fat C & $9.19^{\mathrm{Fh}}$ & $9.50 \mathrm{Fg}$ & $9.69^{\mathrm{Ff}}$ & $9.82^{\mathrm{Fe}}$ & $10.03^{\mathrm{Gd}}$ & $10.18^{\mathrm{Gc}}$ & $10.35^{\mathrm{Gb}}$ & $10.49 \mathrm{Ga}$ & 9.91 \\
\hline Free fat $\mathrm{C}$ & $9.98^{\mathrm{Eh}}$ & 10.19Eg & 10.27 Ef & $10.36^{\mathrm{Ee}}$ & $10.43^{\mathrm{Fd}}$ & $10.48^{\mathrm{Fc}}$ & $10.71^{\mathrm{Fb}}$ & $10.86 \mathrm{Fa}$ & 10.41 \\
\hline A1 & $11.67^{\mathrm{Ah}}$ & $11.79^{\mathrm{Ag}}$ & $11.84^{\mathrm{Af}}$ & $11.90^{\mathrm{Ae}}$ & $12.00^{\mathrm{Ad}}$ & 12.19Ac & $12.25^{\mathrm{Ab}}$ & $12.33^{\mathrm{Aa}}$ & 12.00 \\
\hline A2 & 11.47 Ah & $11.51^{\mathrm{Ag}}$ & $11.64^{\mathrm{Af}}$ & $11.69^{A e}$ & $11.78^{\mathrm{Ad}}$ & $11.95^{\mathrm{AC}}$ & $12.10^{\mathrm{Ab}}$ & $12.15^{\mathrm{Aa}}$ & 11.79 \\
\hline V1 & $11.34^{\mathrm{Bh}}$ & $11.40^{\mathrm{Bg}}$ & $11.44^{\mathrm{Bf}}$ & $11.49^{\mathrm{Be}}$ & $11.57^{\mathrm{Bd}}$ & $11.72^{\mathrm{Bc}}$ & $11.79^{\mathrm{Bb}}$ & $11.89^{\mathrm{Ba}}$ & 11.58 \\
\hline V2 & $10.99^{\mathrm{Bh}}$ & $11.13^{\mathrm{Bg}}$ & $11.20^{\mathrm{Bf}}$ & $11.35^{\mathrm{Be}}$ & $11.45^{\mathrm{Cd}}$ & $11.57^{\mathrm{Cc}}$ & $11.64^{\mathrm{Cb}}$ & $11.72^{\mathrm{Ca}}$ & 11.38 \\
\hline V3 & $10.64^{\mathrm{Ch}}$ & $10.83^{\mathrm{Cg}}$ & $10.91^{\mathrm{Cf}}$ & $11.10^{\mathrm{Ce}}$ & $11.22^{\mathrm{Dd}}$ & $11.32^{\mathrm{Dc}}$ & $11.38^{\mathrm{Db}}$ & $11.53^{\mathrm{Da}}$ & 11.12 \\
\hline V4 & $10.30^{\mathrm{Dh}}$ & $10.53^{\mathrm{Dg}}$ & $10.64^{\mathrm{Df}}$ & $10.75^{\mathrm{De}}$ & $10.91^{\mathrm{Ed}}$ & $11.04^{\mathrm{Ec}}$ & $11.15^{\text {Eb }}$ & $11.23^{\mathrm{Ea}}$ & 10.82 \\
\hline
\end{tabular}


Table 5. TN/DM (\%) and SN/TN (\%) contents of free fat soft cheese along storage period for 120 days at $5 \pm 1 \stackrel{\circ}{ } \mathrm{C}$

\begin{tabular}{|c|c|c|c|c|c|c|c|c|c|}
\hline \multirow{3}{*}{ Treatments } & \multicolumn{8}{|c|}{ Storage period (days) } & \multirow{3}{*}{ TRT } \\
\hline & 0 & 7 & 15 & 21 & 30 & 60 & 90 & 120 & \\
\hline & \multicolumn{8}{|c|}{ TN/DM \% } & \\
\hline Full fat C & $5.04^{\mathrm{Eg}}$ & $5.06^{\mathrm{Ef}}$ & $5.08^{\mathrm{Ee}}$ & $5.10^{\mathrm{Ec}}$ & $5.15^{\mathrm{Eb}}$ & $5.22^{\mathrm{Ea}}$ & $5.09^{\mathrm{Ed}}$ & $4.86^{\mathrm{Fh}}$ & 5.07 \\
\hline Free fat $\mathrm{C}$ & $6.67^{\mathrm{Df}}$ & $6.80^{\mathrm{De}}$ & $6.84^{\mathrm{Dd}}$ & $6.91^{\mathrm{Dc}}$ & $7.03^{\mathrm{Db}}$ & $7.13^{\mathrm{Da}}$ & $6.18^{\mathrm{Dg}}$ & $5.61^{\mathrm{Eh}}$ & 6.65 \\
\hline A1 & $7.32^{\mathrm{Af}}$ & $7.34^{\mathrm{Ae}}$ & $7.38^{\mathrm{Ad}}$ & $7.43^{\mathrm{Ac}}$ & $7.47^{\mathrm{Ab}}$ & $7.56^{\mathrm{Aa}}$ & $6.70^{\mathrm{Ag}}$ & $6.16^{\mathrm{Ah}}$ & 7.17 \\
\hline $\mathbf{A} 2$ & $7.14^{\mathrm{Af}}$ & 7. $27^{\mathrm{Ae}}$ & $7.29^{\mathrm{Ad}}$ & $7.36^{\mathrm{Ac}}$ & $7.43^{\mathrm{Ab}}$ & $7.51^{\mathrm{Aa}}$ & $6.62^{\mathrm{Ag}}$ & $6.09^{\mathrm{Ah}}$ & 7.09 \\
\hline V1 & $7.05^{\mathrm{Bf}}$ & $7.12^{\mathrm{Be}}$ & $7.21^{\mathrm{Bd}}$ & $7.26^{\mathrm{Bc}}$ & $7.37^{\mathrm{Bb}}$ & $7.44^{\mathrm{Ba}}$ & $6.56^{\mathrm{Bg}}$ & $6.02^{\mathrm{Bh}}$ & 7.01 \\
\hline V2 & $6.97^{\mathrm{Bf}}$ & $7.08^{\mathrm{Be}}$ & $7.17^{\mathrm{Bd}}$ & $7.22^{\mathrm{Bc}}$ & $7.31^{\mathrm{Bb}}$ & $7.40^{\mathrm{Ba}}$ & $6.51^{\mathrm{Bg}}$ & $5.94^{\mathrm{Bh}}$ & 6.95 \\
\hline V3 & $6.93^{\mathrm{Cf}}$ & $6.98^{\mathrm{Ce}}$ & $7.02^{\mathrm{Cd}}$ & $7.12^{\mathrm{Cc}}$ & $7.19^{\mathrm{Cb}}$ & $7.26^{\mathrm{Ca}}$ & $6.43^{\mathrm{Cg}}$ & $5.83^{\mathrm{Ch}}$ & 6.85 \\
\hline V4 & $6.87^{\mathrm{Cf}}$ & $6.91^{\mathrm{Ce}}$ & $6.93^{\mathrm{Cd}}$ & $7.03^{\mathrm{Cc}}$ & $7.13^{\mathrm{Cb}}$ & $7.23^{\mathrm{Ca}}$ & $6.34^{\mathrm{Cg}}$ & $5.67^{\mathrm{Dh}}$ & 6.76 \\
\hline \multicolumn{10}{|c|}{ SN/TN \% } \\
\hline Full fat C & $5.69 \mathrm{Gh}$ & $7.08^{\mathrm{Hg}}$ & $8.12^{\mathrm{Hf}}$ & $8.91^{\mathrm{Ge}}$ & $9.95^{\mathrm{Ld}}$ & $11.74^{\mathrm{Hc}}$ & $13.38^{\mathrm{Lb}}$ & $14.37^{\mathrm{Ha}}$ & 9.90 \\
\hline Free fat $\mathrm{C}$ & $6.79^{\mathrm{Fh}}$ & $7.84^{\mathrm{Gg}}$ & $8.47^{\mathrm{Gf}}$ & $9.57^{\mathrm{Ge}}$ & $10.30^{\mathrm{Kd}}$ & $12.06^{\mathrm{Gc}}$ & $14.34^{\mathrm{Jb}}$ & $16.18^{\mathrm{Ga}}$ & 10.69 \\
\hline A1 & $8.82^{\mathrm{Dh}}$ & $10.17^{\mathrm{Eg}}$ & $10.55^{\mathrm{Ef}}$ & $11.78^{\mathrm{Ee}}$ & $12.66^{\mathrm{Hd}}$ & $13.84^{\mathrm{Ec}}$ & $16.30^{\mathrm{Gb}}$ & $18.45^{\mathrm{Ea}}$ & 12.82 \\
\hline $\mathbf{A} 2$ & $7.89^{\mathrm{Eh}}$ & $9.32^{\mathrm{Fg}}$ & $9.96^{\mathrm{Ff}}$ & $11.22^{\mathrm{Fe}}$ & $12.11^{\mathrm{ld}}$ & $13.25^{\mathrm{Fc}}$ & $15.60^{\mathrm{Hb}}$ & $17.75^{\mathrm{Fa}}$ & 12.14 \\
\hline V1 & $12.50^{\mathrm{Ah}}$ & $13.29^{A g}$ & $14.50^{\mathrm{Af}}$ & $15.34^{\mathrm{Ae}}$ & $16.43^{\mathrm{Ad}}$ & $17.38^{\mathrm{Ac}}$ & $19.90^{\mathrm{Ab}}$ & $22.27^{\mathrm{Aa}}$ & 16.45 \\
\hline V2 & $11.27^{\mathrm{Bh}}$ & $12.71^{\mathrm{Bg}}$ & $13.20^{\mathrm{Bf}}$ & $14.38^{\mathrm{Be}}$ & $15.58^{\mathrm{Bd}}$ & $16.67^{\mathrm{Bc}}$ & $19.22^{\mathrm{Bb}}$ & $21.54^{\mathrm{Ba}}$ & 15.57 \\
\hline V3 & $10.66^{\mathrm{Bh}}$ & $12.00^{\mathrm{Cg}}$ & $12.56^{\mathrm{Cf}}$ & $13.52^{\mathrm{Ce}}$ & $14.77^{\mathrm{Dd}}$ & $15.87^{\mathrm{Cc}}$ & $17.83^{\mathrm{Cb}}$ & $20.80^{\mathrm{Ca}}$ & 14.75 \\
\hline V4 & $10.04^{\mathrm{Ch}}$ & $11.30^{\mathrm{Dg}}$ & $12.00^{\mathrm{Df}}$ & $12.76^{\mathrm{De}}$ & $13.92^{\mathrm{Ed}}$ & $15.15^{\mathrm{Dc}}$ & $17.11^{\mathrm{Db}}$ & $19.59^{\mathrm{Da}}$ & 13.98 \\
\hline
\end{tabular}

SN/TN: Soluble Nitrogen / Total Nitrogen

Table 6. Soluble tryptophan $(\mathrm{mg} / 100 \mathrm{~g})$ and Tyrosine $(\mathrm{mg} / 100 \mathrm{~g})$ of free fat soft cheese along storage period for 120 days at $5 \pm 1^{\circ} \mathrm{C}$

\begin{tabular}{|c|c|c|c|c|c|c|c|c|c|}
\hline \multirow{3}{*}{ Treatments } & \multicolumn{8}{|c|}{ Storage period (days) } & \multirow{3}{*}{ TRT } \\
\hline & 0 & 7 & 15 & 21 & 30 & 60 & 90 & 120 & \\
\hline & \multicolumn{8}{|c|}{ Tyrosine $(\mathrm{mg} / \mathbf{1 0 0 g})$} & \\
\hline Full fat C & $40.33^{\mathrm{Gh}}$ & $43.60^{\mathrm{Hg}}$ & $48.20^{\mathrm{Hf}}$ & $51.50^{\mathrm{He}}$ & $54.23^{\mathrm{Hd}}$ & $57.40^{\mathrm{Gc}}$ & $60.53^{\mathrm{Gb}}$ & $64.30^{\mathrm{Fa}}$ & 52.51 \\
\hline Free fat $\mathrm{C}$ & $43.30^{\mathrm{Fh}}$ & $46.53^{\mathrm{Gg}}$ & $49.50^{\mathrm{Gf}}$ & $53.63^{\mathrm{Ge}}$ & $57.93^{\mathrm{Gd}}$ & $59.23^{\mathrm{Fc}}$ & $63.80^{\mathrm{Fb}}$ & $68.17^{\mathrm{Fa}}$ & 55.26 \\
\hline A1 & $53.83^{\mathrm{Dh}}$ & $57.70^{\mathrm{Eg}}$ & $60.37^{\mathrm{Ef}}$ & $63.43^{\mathrm{Ee}}$ & $66.70^{\mathrm{Ed}}$ & $71.13^{\mathrm{Dc}}$ & $75.80^{\mathrm{Db}}$ & $79.90^{\mathrm{Da}}$ & 66.11 \\
\hline A2 & $50.40^{\mathrm{Eh}}$ & $54.63^{\mathrm{Fg}}$ & $58.53^{\mathrm{Ff}}$ & $61.13^{\mathrm{Fe}}$ & $64.80^{\mathrm{Fd}}$ & $68.50^{\mathrm{Ec}}$ & $72.10^{\mathrm{Eb}}$ & $75.33^{\mathrm{Ea}}$ & 63.18 \\
\hline V1 & $63.80^{\mathrm{Ah}}$ & $66.10^{\mathrm{Ag}}$ & $68.70^{\mathrm{Af}}$ & $71.83^{\mathrm{Ae}}$ & $76.90^{\mathrm{Ad}}$ & $81.67^{A c}$ & $87.90^{A b}$ & $92.93^{\mathrm{Aa}}$ & 76.23 \\
\hline V2 & $61.60^{\mathrm{Ah}}$ & $63.46^{\mathrm{Bg}}$ & $66.60^{\mathrm{Bf}}$ & $69.53^{\mathrm{Be}}$ & $74.80^{\mathrm{Bd}}$ & $79.57^{A c}$ & $84.20^{\mathrm{Ab}}$ & $89.50^{\mathrm{Aa}}$ & 73.66 \\
\hline V3 & $58.33^{\mathrm{Bh}}$ & $61.23^{\mathrm{Cg}}$ & $64.60^{\mathrm{Cf}}$ & $67.33^{\mathrm{Ce}}$ & $72.57^{\mathrm{Cd}}$ & $77.43^{\mathrm{Bc}}$ & $81.50^{\mathrm{Bb}}$ & $85.57^{\mathrm{Ba}}$ & 71.07 \\
\hline \multirow[t]{2}{*}{ V4 } & $56.20^{\mathrm{Ch}}$ & $59.27^{\mathrm{Dg}}$ & $62.80^{\mathrm{Df}}$ & $65.73^{\mathrm{De}}$ & $70.30^{\mathrm{Dd}}$ & $75.30^{\mathrm{Cc}}$ & $79.30^{\mathrm{Cb}}$ & $82.80^{\mathrm{Ca}}$ & 68.96 \\
\hline & \multicolumn{8}{|c|}{ Tryptophan $(\mathrm{mg} / \mathbf{1 0 0 g})$} & \\
\hline Full fat C & $28.33^{\mathrm{Kh}}$ & $30.53^{\mathrm{Kg}}$ & $32.70^{\mathrm{Kf}}$ & $35.63^{\mathrm{Le}}$ & $39.77^{\mathrm{Kd}}$ & $45.20^{\mathrm{Kc}}$ & $49.50^{\mathrm{Jb}}$ & $53.30^{\mathrm{Ka}}$ & 39.37 \\
\hline Free fat C & $31.80^{\mathrm{Jh}}$ & $35.40^{\mathrm{Kg}}$ & $37.50^{\mathrm{Kf}}$ & $41.40^{\mathrm{Ke}}$ & $45.13^{\mathrm{Jd}}$ & $50.20^{\mathrm{Jc}}$ & $54.30^{\mathrm{lb}}$ & $59.60^{\mathrm{la}}$ & 44.41 \\
\hline A1 & $40.33^{\mathrm{Eh}}$ & $43.80^{\mathrm{Eg}}$ & $47.80^{\mathrm{Df}}$ & $50.66^{\mathrm{Ke}}$ & $54.13^{\mathrm{Ed}}$ & $59.03^{\mathrm{Ec}}$ & $62.80^{\mathrm{Eb}}$ & $69.80^{\mathrm{Da}}$ & 53.55 \\
\hline A2 & $38.60^{\mathrm{Fh}}$ & $41.60^{\mathrm{Gg}}$ & $45.57^{\mathrm{Ff}}$ & $48.40^{\mathrm{Fe}}$ & $51.60^{\mathrm{Fd}}$ & $55.57^{\mathrm{Gc}}$ & $60.10^{\mathrm{Fb}}$ & $66.90^{\mathrm{Fa}}$ & 51.04 \\
\hline V1 & $49.50^{\mathrm{Ah}}$ & $53.70^{\mathrm{Ag}}$ & $56.87^{\mathrm{Af}}$ & $60.20^{\mathrm{Ae}}$ & $64.80^{\mathrm{Ad}}$ & $69.20^{A c}$ & $73.80^{\mathrm{Ab}}$ & $80.20^{\mathrm{Aa}}$ & 63.53 \\
\hline V2 & $47.23^{A h}$ & $51.50^{\mathrm{Ag}}$ & $55.20^{\mathrm{Af}}$ & $58.20^{\mathrm{Ae}}$ & $61.63^{\mathrm{Ad}}$ & $65.77^{A c}$ & $71.50^{\mathrm{Ab}}$ & $78.20^{\mathrm{Aa}}$ & 61.15 \\
\hline V3 & $44.40^{\mathrm{Ch}}$ & $49.10^{\mathrm{Bg}}$ & $52.57^{\mathrm{Bf}}$ & $55.77^{\mathrm{Ce}}$ & $59.30^{\mathrm{Bd}}$ & $62.60^{\mathrm{Cc}}$ & $67.30^{\mathrm{Cb}}$ & $75.50^{\mathrm{Ba}}$ & 58.32 \\
\hline V4 & $42.70^{\mathrm{Dh}}$ & $46.30^{\mathrm{DEg}}$ & $49.33^{C f}$ & $52.53^{\mathrm{De}}$ & $56.37^{\mathrm{Cd}}$ & $60.66^{\mathrm{Dc}}$ & $65.20^{\mathrm{Db}}$ & $72.40^{\mathrm{Ca}}$ & 55.69 \\
\hline
\end{tabular}


Soluble tyrosine content was higher in treatment $\mathrm{V} 1$ free fat soft cheese $(63.80 \mathrm{mg} / 100 \mathrm{~g})$, Meanwhile, the lowest soluble tyrosine content was detected in control fresh full-fat soft cheese $(40.33 \mathrm{mg} / 100 \mathrm{~g})$. Soluble tyrosine sharply increased along the storage period till the end of storage period (120 days). It reached 92.93-64.30 $\mathrm{mg} / 100 \mathrm{~g}$ in treatment $\mathrm{V} 1$ free fat soft cheese and control full-fat soft cheese, respectively. The highest (TRT) was recorded in treatment $V 1$ free fat soft cheese, followed by treatment V2 free fat soft cheese, while, the lowest TRT was found in control full-fat soft cheese. Comparable results were reported by Badawi and Kebary (1998); El-Abd et al (2003) as well as Kebary et al (2006) who attributed their results to the low moisture content and low water activity, which in turn suppress the growth of proteolytic bacteria and inhibit proteolysis activity themselves.

\section{(4) Total Volatile Fatty Acids (TVFA)}

Table (7) shows the TVFA (ml $0.1 \mathrm{~N}$ $\mathrm{NaOH} / 100 \mathrm{~g}$ ) in cheese of free fat soft cheese along storage period for 120 days at $5 \pm 1^{\circ} \mathrm{C}$. The TVFA values of fresh cheese were higher in treatment $\mathrm{V}_{1}(6.07 \mathrm{ml} 0.1 \mathrm{~N} \mathrm{NaOH} / 100 \mathrm{~g})$, however the lowest was detected in control fresh free fat soft cheese $(2.60 \mathrm{ml} 0.1 \mathrm{~N} \mathrm{NaOH} / 100 \mathrm{~g})$. TVFA sharply increased along the storage period at the end of storage period (120 days). It reached to (29.60 $17.20 \mathrm{ml} 0.1 \mathrm{~N} \mathrm{NaOH} / 100 \mathrm{~g}$ ) in treatment $\mathrm{V} 1$ and free fat, respectively. The highest content (TRT) was recorded in treatment $\mathrm{V} 1$, followed by $\mathrm{V} 2$, whereas, the lowest TRT was detected in free fat. The obtained results of accumulation of TVFA increased with the increase of the storage period in all cheese samples. Comparable results were reported by Swelam, (2005), Kebary et al (2006) and Kholif et al (2010).

Table 7. TVFA $(\mathrm{ml} 0.1 \mathrm{~N} \mathrm{NaOH} / 100 \mathrm{~g})$ cheese of free fat soft cheese along storage period for 120 days at $5 \pm 1^{\circ} \mathrm{C}$

\begin{tabular}{|c|c|c|c|c|c|c|c|c|c|c|}
\hline \multirow{2}{*}{ Treatments } & \multicolumn{7}{|c|}{ Storage period (days) } & \multirow{2}{*}{ TRT } \\
\cline { 2 - 9 } & $\mathbf{0}$ & $\mathbf{7}$ & $\mathbf{1 5}$ & $\mathbf{2 1}$ & $\mathbf{3 0}$ & $\mathbf{6 0}$ & $\mathbf{9 0}$ & $\mathbf{1 2 0}$ & \\
\cline { 2 - 9 } & \multicolumn{7}{|c|}{ TVFA $\mathbf{( m l} \mathbf{0 . 1} \mathbf{N} \mathbf{N a O H} / \mathbf{1 0 0 g}$ cheese) } \\
\hline Full fat C & $3.00^{\mathrm{Gh}}$ & $5.20^{\mathrm{Gg}}$ & $7.70^{\mathrm{Gf}}$ & $10.40^{\mathrm{Ge}}$ & $12.70^{\mathrm{Gd}}$ & $14.60^{\mathrm{Dc}}$ & $17.60^{\mathrm{Gb}}$ & $20.70^{\mathrm{Ga}}$ & 11.49 \\
Free fat C & $2.60^{\mathrm{Hh}}$ & $4.90^{\mathrm{Hg}}$ & $7.50^{\mathrm{Hf}}$ & $9.40^{\mathrm{He}}$ & $10.40^{\mathrm{Hd}}$ & $12.10^{\mathrm{Fc}}$ & $13.70^{\mathrm{Hb}}$ & $17.20^{\mathrm{Ha}}$ & 9.73 \\
A1 & $3.50^{\mathrm{Eh}}$ & $6.10^{\mathrm{Eg}}$ & $9.10^{\mathrm{Ef}}$ & $12.60^{\mathrm{Ee}}$ & $15.80^{\mathrm{Ed}}$ & $18.80^{\mathrm{Dc}}$ & $21.80^{\mathrm{Eb}}$ & $25.40^{\mathrm{Ea}}$ & 14.14 \\
A2 & $3.10^{\mathrm{Fh}}$ & $5.50^{\mathrm{Fg}}$ & $8.50^{\mathrm{Ff}}$ & $11.50^{\mathrm{Fe}}$ & $14.70^{\mathrm{Fd}}$ & $17.50^{\mathrm{Ec}}$ & $20.90^{\mathrm{Fb}}$ & $24.20^{\mathrm{Fa}}$ & 13.24 \\
V1 & $6.07^{\mathrm{Ah}}$ & $8.87^{\mathrm{Ag}}$ & $12.40^{\mathrm{Af}}$ & $16.10^{\mathrm{Ae}}$ & $19.30^{\mathrm{Ad}}$ & $22.40^{\mathrm{Ac}}$ & $25.70^{\mathrm{Ab}}$ & $29.60^{\mathrm{Aa}}$ & 17.56 \\
V2 & $5.40^{\mathrm{Bh}}$ & $8.10^{\mathrm{Bg}}$ & $11.47^{\mathrm{Bf}}$ & $15.20^{\mathrm{Be}}$ & $18.10^{\mathrm{Bd}}$ & $21.20^{\mathrm{Bc}}$ & $24.40^{\mathrm{Bb}}$ & $28.20^{\mathrm{Ba}}$ & 16.51 \\
V3 & $4.47^{\mathrm{Ch}}$ & $7.13^{\mathrm{Cg}}$ & $10.50^{\mathrm{Cf}}$ & $14.20^{\mathrm{Ce}}$ & $17.40^{\mathrm{Cd}}$ & $20.20^{\mathrm{Cc}}$ & $23.27^{\mathrm{Cb}}$ & $27.10^{\mathrm{Ca}}$ & 15.54 \\
V4 & $3.90^{\mathrm{Dh}}$ & $6.60^{\mathrm{Dg}}$ & $9.57^{\mathrm{Df}}$ & $13.30^{\mathrm{De}}$ & $16.70^{\mathrm{Dd}}$ & $19.60^{\mathrm{Cc}}$ & $22.77^{\mathrm{Db}}$ & $26.10^{\mathrm{Da}}$ & 14.83 \\
\hline
\end{tabular}

\section{(B) Microbiological analyses}

Total Viable Bacterial counts (TVBC) were illustrated in Fig. (1) reveal that there were significant differences in the total viable bacterial counts (TVBC) in all of the examined samples of soft cheese, when fresh and along the storage. The highest TVBC were recorded in $\mathrm{V} 1$ free fat soft cheese $(8.18 \mathrm{log} \mathrm{cfu} / \mathrm{g})$, followed by V2 free fat soft cheese $(8.00 \log \mathrm{cfu} / \mathrm{g})$. On the contrary, the lowest total viable counts were in treatment $A 2$ free fat soft cheese (7.18 log cfu/g). Total viable bacterial count increased along the storage period at (30 days) and then decreased along the storage at the end of during the storage (120 days).
Lactic acid bacterial counts (LABC) were higher in all free fat soft cheese samples (more than $1 x$ $10^{7} \mathrm{cfu} / \mathrm{g}$ ). LAB counts slightly increased along the first 30 days of the storage, followed by significant reduction till the end of the storage. LAB counts ranged from 8.83 to $8.04 \mathrm{log} \mathrm{cfu} / \mathrm{g}$ in treatment $\mathrm{V} 1$ and treatment $A 2$, respectively, during 30 days of storage, LAB counts increased and ranged from 9.04 to $8.57 \mathrm{log} \mathrm{cfu} / \mathrm{g}$. The highest counts were found in free fat soft cheese samples V1 (8.83log $\mathrm{cfu} / \mathrm{g})$, followed by $\mathrm{V} 2$ (8.68log $\mathrm{cfu} / \mathrm{g})$. Whereas, the lowest counts were in treatment $A 2$ and $A 1$ (8.04 and $8.20 \log \mathrm{cfu} / \mathrm{g}$, respectively). The highest LAB counts were detected in V1 and V2 free fat soft cheese treatments, which could be due to the 
lower acidity (\%), compared with all other treatment. These results agreed with those finding of Kebary et al (2007); Badwi et al (2008); ElSonbaty (2008); Abou Ayana and Amal (2015).

Psychrophilic bacterial counts of free fat soft cheese along the storage period for 120 days at $5 \pm 1^{\circ} \mathrm{C}$ are shown in Fig. (1). Psychrophilic bacterial counts were detected after 7 days of storage period till the end of 120 days. Their counts were higher in control fresh full-fat soft cheese (4.95 log $\mathrm{cfu} / \mathrm{g})$. While, the lowest counts were in treatment V1 (3.70 log cfu/g). Their counts slightly increased during the storage until the end of the storage (120days), reaching to (5.62 - $4.51 \mathrm{log} \mathrm{cfu} / \mathrm{g})$ in the control full-fat soft cheese and treatment $\mathrm{V} 1$, respectively. The highest (TRT) was recorded in control full-fat soft cheese, followed by control free fat soft cheese, whereas, the least TRT treatment V1.

Yeasts and moulds counts were only detected after 15 days of during the storage till the end of 120 days. Yeasts and moulds counts were higher in control fresh full-fat soft cheese (3.3 log cfu/g), while the lowest were in treatment V1 (2 log cfu/g), followed by V2 (2.30log cfu/g) in fresh free fat soft cheese samples. Yeast and moulds count slightly increased as the storage period progressed at the end of the storage period (120 days), Yeast and mould counts reached to (3.9 - $2.78 \mathrm{log} \mathrm{cfu} / \mathrm{g})$ in control full-fat soft cheese and treatment $\mathrm{V} 1$, respectively. The highest (TRT) was recoded in control full-fat soft cheese, followed by control free fat soft cheese, whereas, the lowest counts were in V1treatment. The present results are in harmony with those given by El-Abd et al (2003) who observed an inhibitory effect of added starter cultures. Thus, the control cheese had always higher yeast and mould counts as compared to cheese from different treatments at any age.

\section{(C) Rheological properties}

Fig. (2) illustrates the rheological properties of full and free fat soft cheese along the storage period for 120 days at $5 \pm 1^{\circ} \mathrm{C}$. Hardness, gumminess, adhesiveness, cohesiveness and chewiness were significantly higher in control fresh full fat soft cheese and along the storage period as compared with all other free fat soft cheese treatments. On the contrary, hardness, gumminess, adhesiveness, cohesiveness and chewiness were significantly the least in free fat soft cheese V4 treatment.

Generally, hardness, gumminess, cohesiveness and chewiness increased significantly in all soft cheese samples among the storage period.
Hardness was significantly higher in control fresh fat soft cheese $(6.23 \mathrm{~N})$ while, the lowest significant hardness was in treatment V4 free fat soft cheese $(2.90 \mathrm{~N})$. Hardness sharply increased along the storage period in all soft cheese treatments till the end of the storage (120 days). It reached to range $(16.10-10.90 \mathrm{~N})$ in control fullfat soft cheese and V4 treatment, respectively. This is expected, since fat breaks up the protein matrix and plays role of lubricant to provide smoothness and softer texture (Dinkci et al 2011) for FFC.

Comparing the obtained values of the cohesiveness by those of the texture profile analysis (TPA) test in fresh cheese sample, results shown in Fig. (2) reveal that cohesiveness values of fresh samples were similar to hardness value, which was higher in control fresh fat soft cheese. Cohesiveness gradually increased along the storage period till 120 days. Hardness and cohesiveness of free fat soft cheese samples were starter culture dependent. In general, TRT for hardness and cohesiveness were significantly higher in control fullfat soft cheese, followed by control free fat soft cheese, while, the lowest was detected in treatment V4.

Gumminess is the force needed to break a semisolid food to a state ready for swallowing and be calculated as hardness $\times$ cohesiveness (Tunick, 2000). Springiness $(\mathrm{mm})$ obtained from the recovery of height during the time between ends of $1^{\text {st }}$ bit and start of $2^{\text {nd }}$ bite (length 1) (Gunasekaran and Ake, 2003).

It could be noticed that, gumminess increased and springiness decreased by increasing of the storage period in all soft cheese samples. Springiness of free fat soft cheese made with $V 1$ free fat soft cheese was the highest when fresh and along the storage period. On the contrary, gumminess was significantly higher in control full-fat soft cheese.

Chewiness is a measurement of the energy prerequisite to masticate cheese into a uniform state where it is ready for swallowing. In sensory forms, it is the energy required to disintegrate the cheese and to change it to consistency suitable for swallowing. It is the secondary parameter derived from hardness $\times$ cohesiveness $\times$ springiness (Gunasekaran and Ake, 2003). Chewiness was higher in control fresh full-fat soft cheese and sharply increased by increasing of the storage period. 

producing lactic acid bacteria as starter microflora
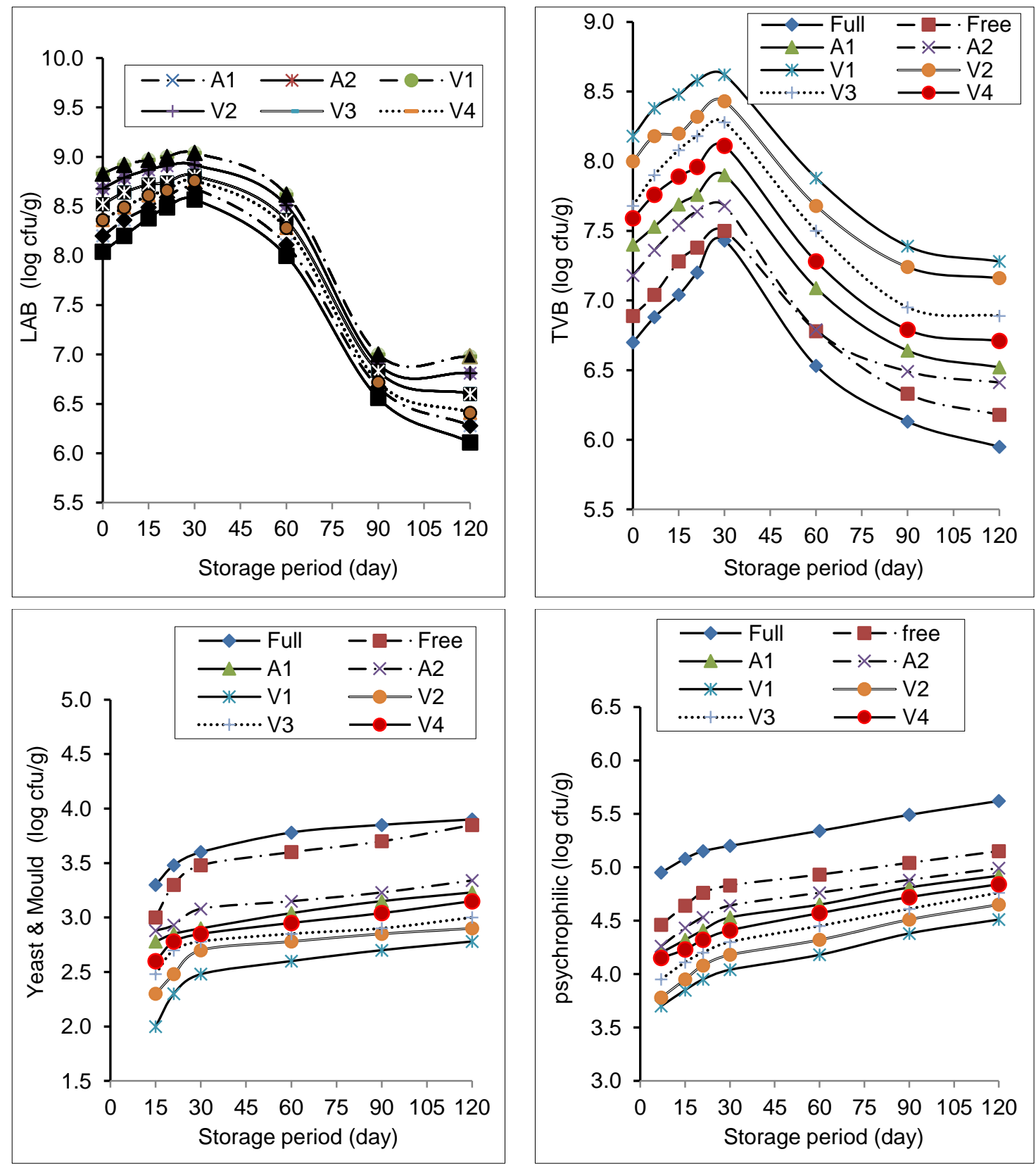

Fig. 1. Microbiological properties of free fat soft cheese along storage period for 120 days at $5 \pm 1^{\circ} \mathrm{C}$. 

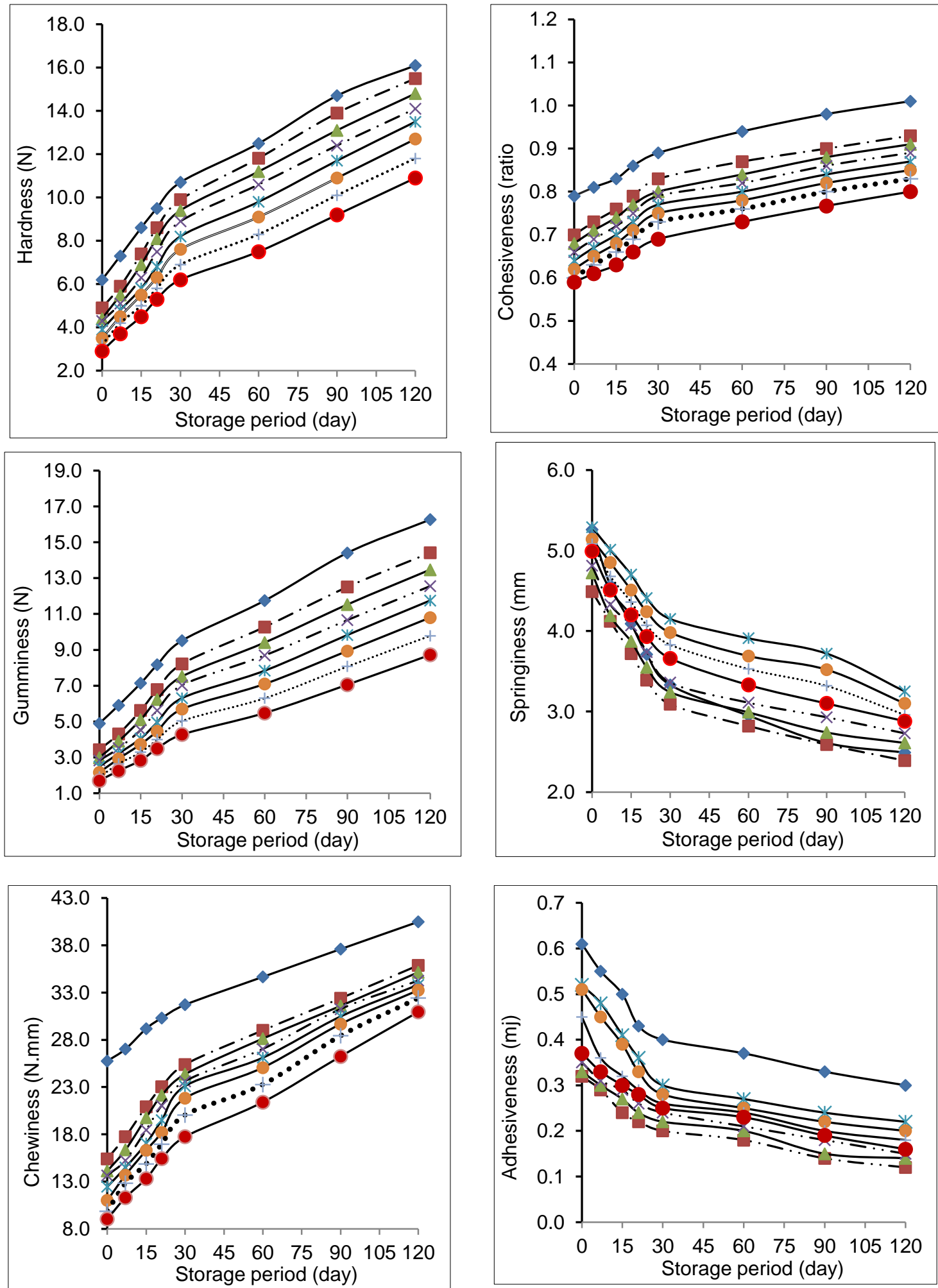

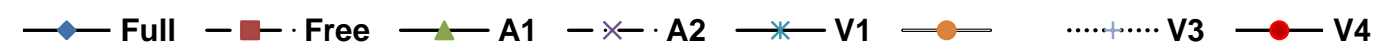

Fig. 2. Rheological properties of free fat soft cheese along the storage period for 120 days at $5 \pm 1^{\circ} \mathrm{C}$. 

producing lactic acid bacteria as starter microflora

Adhesiveness (mj) of full-fat soft cheese (control) was significantly higher than free fat soft cheese treatments along the storage period for 120 days at $5 \pm 1^{\circ} \mathrm{C}$. Adhesiveness of control full-fat soft cheese, followed by treatment $V 1$ free fat soft cheese was significantly the highest.

\section{(D) Sensory evaluation}

The results presented in Table (8) show flavor (taste and aroma), body and texture and appearance scores of free fat soft cheese along the storage period for 120 days at $5 \pm 1^{\circ} \mathrm{C}$. Flavor scores were significantly higher in control fresh full fat soft cheese (36.2 points), followed by $\mathrm{V} 1$ and V2 free fat soft cheese. Whereas, the lowest scores were detected in control fresh free fat soft cheese (32.9 points). Flavor scores gradually increased by increasing the storage period till 90 days, then decreased. Flavor scores ranged from to 36.2 to 32.9 in fresh samples and increased to range 48 to 43.8 after 90 days.

Table 8. Flavor (50 points), Body \& Texture (40 points) and appearance (10 points) of free fat soft cheese along storage period for 120 days at $5 \pm 1^{\circ} \mathrm{C}$

\begin{tabular}{|c|c|c|c|c|c|c|c|c|c|}
\hline \multirow[t]{3}{*}{ Treatments } & \multicolumn{8}{|c|}{ Storage period (days) } & \multirow[t]{3}{*}{ TRT } \\
\hline & 0 & 7 & 15 & 21 & 30 & 60 & 90 & 120 & \\
\hline & \multicolumn{8}{|c|}{ Flavor (50 points) } & \\
\hline Full fat C & $36.2^{\mathrm{Ah}}$ & $39.9^{\mathrm{Ag}}$ & $41.8^{\mathrm{Af}}$ & $44.7^{\mathrm{Ae}}$ & $45.4^{\mathrm{Ad}}$ & $46.5^{\mathrm{Ac}}$ & $47.5^{\mathrm{Ab}}$ & $48.0^{\mathrm{Aa}}$ & 43.7 \\
\hline Free fat C & $32.9^{\mathrm{Fh}}$ & $35.8^{\mathrm{Fg}}$ & $38^{\mathrm{Ff}}$ & $40.2^{\mathrm{Ge}}$ & $41.5^{\mathrm{Fd}}$ & $42.5^{\mathrm{Fc}}$ & $43^{\mathrm{Gb}}$ & $43.8^{\mathrm{Ga}}$ & 39.71 \\
\hline A1 & $33.3^{\mathrm{Eh}}$ & $38.4^{\mathrm{Eg}}$ & $40.4^{\mathrm{Df}}$ & $41.8^{\mathrm{Fe}}$ & $42.5^{\mathrm{Ed}}$ & $44.4^{\mathrm{Ec}}$ & $44.8^{\mathrm{Fb}}$ & $46.3^{\mathrm{Ea}}$ & 41.49 \\
\hline A2 & $33.1^{\mathrm{Eh}}$ & $38.2^{\mathrm{Eg}}$ & $40.1^{\mathrm{Ef}}$ & $41.5^{\mathrm{Ge}}$ & $42.1^{\mathrm{Fd}}$ & $43.1^{\mathrm{Fc}}$ & $44.6^{\mathrm{Fb}}$ & $45^{\mathrm{Fa}}$ & 40.96 \\
\hline V1 & $36.1^{\mathrm{Ah}}$ & $39.3^{\mathrm{Bg}}$ & $41.4^{\mathrm{Bf}}$ & $44.3^{\mathrm{Be}}$ & $45^{\mathrm{Ad}}$ & $46.3^{\mathrm{Ac}}$ & $47.1^{\mathrm{Bb}}$ & $47.8^{\mathrm{Aa}}$ & 43.41 \\
\hline V2 & $35^{\mathrm{Bh}}$ & $39.1^{\mathrm{Cg}}$ & $41.2^{\mathrm{Bf}}$ & $43.4^{\mathrm{Ce}}$ & $44.4^{\mathrm{Bd}}$ & $45.8^{\mathrm{Bc}}$ & $46.9^{\mathrm{Cb}}$ & $47.5^{\mathrm{Ba}}$ & 42.91 \\
\hline V3 & $34.4^{\mathrm{Ch}}$ & $38.8^{\mathrm{Dg}}$ & $41^{\mathrm{Cf}}$ & $43.1^{\mathrm{De}}$ & $43.9^{\mathrm{Cd}}$ & $45.6^{\mathrm{Cc}}$ & $46.3^{\mathrm{Db}}$ & $46.8^{\mathrm{Ca}}$ & 42.49 \\
\hline \multirow[t]{2}{*}{ V4 } & $34^{\mathrm{Dh}}$ & 38. $\mathrm{Dg}$ & $40.8^{\mathrm{Cf}}$ & $42.3^{\mathrm{Ee}}$ & $43.00^{\mathrm{Dd}}$ & $45.1^{\mathrm{Dc}}$ & $46^{\mathrm{Eb}}$ & $46.7^{\mathrm{Da}}$ & 42.06 \\
\hline & \multicolumn{8}{|c|}{ Body \& Texture (40 points) } & \\
\hline Full fat C & $33.30^{\mathrm{Af}}$ & $33.70^{\mathrm{Ee}}$ & $34.00 \mathrm{Fd}$ & $34.60 \mathrm{Fc}$ & $35.50^{\mathrm{Eb}}$ & $35.90^{\mathrm{Fa}}$ & $32.90^{\mathrm{Eg}}$ & $31.80^{\mathrm{Dh}}$ & 33.96 \\
\hline Free fat $\mathrm{C}$ & $31.30 \mathrm{Fg}$ & $31.67^{\mathrm{Gf}}$ & $32.70^{\mathrm{Gd}}$ & $33.20^{\mathrm{Gc}}$ & $33.60^{\mathrm{Fb}}$ & $33.90^{\mathrm{Fa}}$ & $31.73^{\mathrm{Ee}}$ & $30.03^{\mathrm{Eh}}$ & 32.27 \\
\hline A1 & $32.77^{\mathrm{Dg}}$ & $33.70^{\mathrm{Ee}}$ & $34.57^{\mathrm{Ed}}$ & $35.5^{\mathrm{Ec}}$ & $35.83^{\mathrm{Eb}}$ & $36.80^{\mathrm{Ea}}$ & $33.57^{\mathrm{CDf}}$ & $32.67^{\mathrm{Dh}}$ & 34.43 \\
\hline A2 & $32.63^{\mathrm{Eg}}$ & $33.40^{\mathrm{Ff}}$ & $33.80^{\mathrm{Gd}}$ & $35.23^{F c}$ & $35.57 \mathrm{~Eb}$ & $36.53^{\mathrm{Ea}}$ & $33.50^{\mathrm{De}}$ & $32.50^{\mathrm{Dh}}$ & 34.15 \\
\hline V1 & $33.97^{\mathrm{Ah}}$ & $35.00^{\mathrm{Af}}$ & $36.80^{\mathrm{Ad}}$ & $37.27^{\mathrm{Ac}}$ & $37.50^{\mathrm{Ab}}$ & $38.00^{\mathrm{Aa}}$ & $36.20^{\mathrm{Ae}}$ & $34.03^{\mathrm{Ag}}$ & 36.10 \\
\hline V2 & $33.73^{\mathrm{Bh}}$ & $34.77^{\mathrm{Bf}}$ & $36.30^{\mathrm{Bd}}$ & $36.90^{\mathrm{Bc}}$ & $37.20^{\mathrm{Bb}}$ & $37.80^{\mathrm{Ba}}$ & $35.87^{\mathrm{Be}}$ & $33.77^{\mathrm{ABg}}$ & 35.79 \\
\hline V3 & $33.20^{\mathrm{Ch}}$ & $34.60^{\mathrm{Cf}}$ & $36.00^{\mathrm{Cd}}$ & $36.57^{\mathrm{CDc}}$ & $36.83^{\mathrm{Cb}}$ & $37.53^{\mathrm{BCa}}$ & $35.60^{\mathrm{Be}}$ & $33.37^{\mathrm{Cg}}$ & 35.46 \\
\hline \multirow[t]{2}{*}{ V4 } & $33.10^{\mathrm{Dg}}$ & $34.20^{\mathrm{De}}$ & $35.00^{\mathrm{Dd}}$ & $36.00^{\mathrm{Ec}}$ & $36.37^{\mathrm{Db}}$ & $37.20^{\mathrm{Da}}$ & $34.17^{\mathrm{Cf}}$ & $33.00^{\mathrm{Ch}}$ & 34.87 \\
\hline & \multicolumn{8}{|c|}{ Appearance (10points) } & \\
\hline Full fat C & $7.3^{\mathrm{Ag}}$ & $8.1^{\mathrm{Ae}}$ & $8.2^{\mathrm{Ad}}$ & $8.3^{\mathrm{Ac}}$ & $8.5^{\mathrm{Ab}}$ & $8.8^{\mathrm{Aa}}$ & $7.4^{\mathrm{Af}}$ & $7.0^{\mathrm{Ah}}$ & 7.95 \\
\hline Free fat $\mathrm{C}$ & $5.9 \mathrm{Fg}$ & $6.3^{\mathrm{Fe}}$ & $6.6^{\mathrm{Fd}}$ & $6.9^{\mathrm{Fc}}$ & $7^{\mathrm{Fb}}$ & $7.2^{\mathrm{Ha}}$ & $6^{\mathrm{Ff}}$ & $5.5^{\mathrm{Hh}}$ & 6.43 \\
\hline A1 & $6.2^{\mathrm{Gg}}$ & $6.7^{\mathrm{Ge}}$ & $7^{\mathrm{Hd}}$ & $7.2^{\mathrm{Gc}}$ & $7.5^{\mathrm{Gb}}$ & $7.7 \mathrm{Fa}$ & $6.3^{\mathrm{Ef}}$ & $6.1^{\mathrm{Fh}}$ & 6.84 \\
\hline A2 & $6^{\mathrm{Hg}}$ & $6.5^{\mathrm{He}}$ & $6.8^{\mathrm{Gd}}$ & $7^{\mathrm{Hc}}$ & $7.2^{\mathrm{Hb}}$ & 7. $4^{\mathrm{Ga}}$ & $6.1^{\mathrm{Ef}}$ & $5.9^{\mathrm{Gh}}$ & 6.63 \\
\hline V1 & $6.8^{\mathrm{Bg}}$ & $7.6^{\mathrm{Be}}$ & $7.9^{\mathrm{Bd}}$ & $8^{\mathrm{Bc}}$ & $8.2^{\mathrm{Bb}}$ & $8.4^{\mathrm{Ba}}$ & $6.9^{\mathrm{Bf}}$ & $6.7^{\mathrm{Bh}}$ & 7.58 \\
\hline V2 & $6.7^{\mathrm{Cg}}$ & 7. $4^{\mathrm{Ce}}$ & $7.7^{\mathrm{Cd}}$ & $7.8^{\mathrm{Cc}}$ & $8^{\mathrm{Cb}}$ & $8.2^{\mathrm{Ca}}$ & $6.8^{\mathrm{Bf}}$ & $6.5^{\mathrm{Ch}}$ & 7.39 \\
\hline V3 & $6.5^{\mathrm{Dg}}$ & 7. $1^{\mathrm{De}}$ & $7.3^{\mathrm{Dd}}$ & $7.6^{\mathrm{Dc}}$ & $7.8^{\mathrm{Db}}$ & $8^{\mathrm{Da}}$ & $6.6^{\mathrm{Cf}}$ & $6.4^{\mathrm{Dh}}$ & 7.16 \\
\hline V4 & $6.3^{\mathrm{Eg}}$ & $6.9^{\mathrm{Ee}}$ & $7.1^{\mathrm{Ed}}$ & $7.5^{\mathrm{Ec}}$ & $7.6^{\mathrm{Eb}}$ & $7.9^{\mathrm{Ea}}$ & $6.4^{\mathrm{Df}}$ & $6.2^{\text {Eh }}$ & 6.99 \\
\hline
\end{tabular}


As with the body and texture (40 points), scores achieved in full and free fat soft cheese along the storage period for 120 days at $5 \pm 1^{\circ} \mathrm{C}$. Body and texture scores were significantly high in fresh free fat soft cheese treatment V1 (33.97 points) as shown in the same Table. While, the lowest scores were in control fresh free fat soft cheese (31.30 points). Generally, body and texture scores gradually increased along the storage period till 60 days of the storage followed, by gradual decrease along the storage (120 days). Body and texture scores obtained in the starter culture types during the storage period are dependent. The highest (TRT) was recoded in treatment $\mathrm{V} 1$ followed, by treatment V2, whereas, the lowest TRT control free fat soft cheese.

Appearance (points) of free fat soft cheese along the storage period for 120 days at $5 \pm 1^{\circ} \mathrm{C}$ were high in control fresh full-fat soft cheese (7.3 points). While, control fresh free fat soft cheese gained the least appearance scores (5.9 points). Appearance gradually increased by increasing the storage period till (60 days), followed by a slight reduction along the remaining period (120 days). There were significant differences in appearance scores between all samples along the storage period. In addition, appearance scores were starter culture type and storage period dependent. The highest (TRT) of appearance score was recoded in control full-fat soft cheese followed by treatment V1 followed by V2 free fat soft cheese. On the contrary, the least TRT of appearance was in control free fat soft cheese.

\section{REFERENCES}

Abou Ayana I.A.A. and Amal E. Ibrahim 2015. Attributes of low-fat Yogurt and Kareish Cheese Made Using Exopolysaccharides Lactic Acid Bacteria. Amer. J. Food Technol., 10, 48-57.

Abou-Donia S.A. 1986. Egyptian Domiati soft white pickled cheese. New Zealand. J. Dairy Sci. Technol. 21, 167-175.

AOAC 2012. Official Methods of Analysis. $19^{\text {th }}$ ed. AOAC International Gaithersburg, MD. pp. 5657.

Badawi R.M. and Kebary K.M.K. 1998. Influence of fat replacers on the quality of low fat Tallage cheese. Proc. of the $7^{\text {th }}$ Egyptian Conf. for Dairy Sci. and Techn. Cairo, Egypt, 7-9 November, pp. 347-365.
Badawi R.M., Hamed A.I., Kebary K.M.K. and ElSayed H.A. 2008. Effect of replacing milk fat with fat replacers on the quality of stirred yoghurt. Egyptian J. Dairy Sci. 36(2), 197-206.

Banks J.M. 2004.The technology of low-fat cheese manufacture. Int. J. of Dairy Technology. 57(4), 199-207.

Bodyfelt F.W., Tobias J. and Trout G.M. 1988. The sensory evaluation of dairy products. Van Nostrand Reinhold. New York, USA, 598, 227-270.

Bourne M.C. 2003. Food texture and viscosity Concept and measurement ( $2^{\text {nd }}$ ed.). New York, NY: Academic Press.

Bourne M.C. 2004. Relation between texture and mastication. J. Texture Stud., 35, 125-143.

De Man J.C., Rogosa M. and Sharp M.E. 1960. A medium for the cultivation of lactobacilli. J. Appl. Bacteriol., 23, 130-136.

Dinkci N., Kesenkas H., Seckin A.K., Kinik O. and Gonc S. 2011. Influence of a vegetable fat blend on the texture, microstructure and sensory properties of kashar cheese. Grasas y. aceites, 62(3), 275-283.

El-Abd M.M., Abd El-Fattah A.M., Osman S.G. and Abd El-Kader R.S. 2003. Effect of some lactic acid bacteria on the properties of low salt Domiati cheese. Egypt. J. Dairy Sci., 31, 125138.

El-Sonbaty A.H. 2008. Studies on some Biochemical changes in Domiati cheese during pickling. Minufiya J. Agric. Res. 25(1), 135-149.

Fenelon M.A. and Guinee T.P. 2000. Primary proteolysis and textural changes during ripening in Cheddar cheeses manufactured to different fat contents. Int. Dairy J. 10, 151-158.

Fenelon M.A., Beresford T.P. and Guinee T.P. 2002. Comparison of different bacterial culture systems for the production of reduced-fat cheddar cheese. Int. J. of Dairy Technology 55, 194-203.

Gunasekaran S. and AK. M.M. 2003. Fundamental rheological methods. Cheese Rheology and Texture. CRC Press, USA, pp. 31-112.

Gutierrez M.N., Trancoso R.N. and Leal R.M.Y. 2013. Texture profile analysis of fresh cheese and Chihuahua cheese using miniature cheese models. Tecnociencia Chihuahua, 7(2), 6574.

Houghtby G.A., Maturin L.J. and Koenig E.K. 1992. Microbiological count methods. In: Marshal R.T. (ed.). Standard Methods for the Examination of Dairy Products $\left(16^{\text {th }}\right.$ ed.). Ameri- 
can Public Health Association, Washington, DC, USA, pp. 213-246.

Kebary K.M.K., Hamed A.I., Zedan A.N. and Beheary A.A.F. 2006. Manufacture of low fat Domiati cheese using Novagel. Egyptian J. Dairy Sci., 34,175-184.

Kebary K.M.K., Hussein S.A., Badawi R.M. and Badran I.I. 2007. Incorporation of bifidobacteria in low fat Labneh. Proc. $10^{\text {th }}$ Egyptian Conf. Dairy Sci. and Technol. pp. 359-375.

Kebary K.M.K., Salem O.M., El-Sonbaty A.H. and El-Sisey A.S. 2002. Impact of low fat replacers on the quality of low fat Edam cheese. Egyptian J. Dairy Sci. 30, 253-266.

Kholif A.M., Mohran G.A., El-Nawawy M., Azza A. Ismail, Salem M.M.E. and Wafaa M. Zaky 2010. Use of Some Lactobacillus Strains to Improve Soft Cheese Quality. World Applied Sci. J. 11(7), 766-774.

Kim M.S. 1989. Enhancing flavor characteristics of semi-soft cheese made from milk concentrated by ultrafiltration. Univ. of Wisconsin-Madison., USA, pp. 313-315.

Law B.A. and Tamime A.Y. 2010. Technology of Cheesemaking. Cheese-ripening and cheese flavour technology. $2^{\text {nd }}$ (ed.). Wiley-Blackwell, Oxford, UK, Chapter 7, 10 p.

Ling E.R. 1963. A Textbook of Dairy Chemistry. $4^{\text {th }}$ ed, Chapman \& Hall, Ltd, London, 2,

Marshall R.T. 1992. Standard Methods for the Examination of Dairy Products. Am. Publ. Health Assoc. (APHA), Washington, DC., USA.

Marshall R.T. 2004. American Public Health Association. Standards Methods for the examination of dairy products, $17^{\text {th }}$ ed Washington, DC., USA.
Michaelidou A., Katsiari M.C., Kondyli E., Voutsinas L.P. and Alichanidis E. 2003. Effect of a commercial adjunct culture on proteolysis in low-fat Feta- type cheese. Int. Dairy J. 13(2-3), 179-189.

Patel A. and Prajapati J.B. 2013. Food and health applications of exopolysaccharides produced by lactic acid bacteria. Adv. Dairy Res., 1, 1-7.

Romeih E.A., Michaelidou A., Biliaderis C.G. and Zerfiridis G.K. 2002. Low-fat white brined cheese made from bovine milk and two commercial fat mimetics, physical and sensory attributes. Inter. Dairy J. 12, 525-540.

SAS. 2009. Statistical Analysis System, SAS User's Guide: Statistics. SAS Institute Inc. Editors, Cary, NC, USA.

Standard I. 1997. Milk, cream and evaporated milk-determination of total solid content (Reference method). Bureau of Indian Standards, IS-12333, Manak Bhavan, New Delhi: BIS.

Swelam S.A.M. 2005. An attempt to improve the quality of Domiati cheese made from pasteurized milk. M.Sc. Thesis, Fac. of Agric., Tanta Univ., Egypt, pp. 89-90.

Tunick M.H. 2000. Rheology of dairy foods that gel, stretch, and fracture. J. Dairy Sci., 83, 1892-1898.

Vakaleris D.G. and Price W.V. 1959. A rapid spectrophotometric method for cheese ripening. J. Dairy Sci., 47, 264-276.

Zhang L., Li X., Ren H., Liu L., Ma L., Li M. and Bi W. 2015. Impact of Using Exopolysaccharides (EPS)-Producing Strain on Qualities of Half-Fat Cheddar Cheese. Inter. J. of Food Properties, 18(7), 1546-1559. 


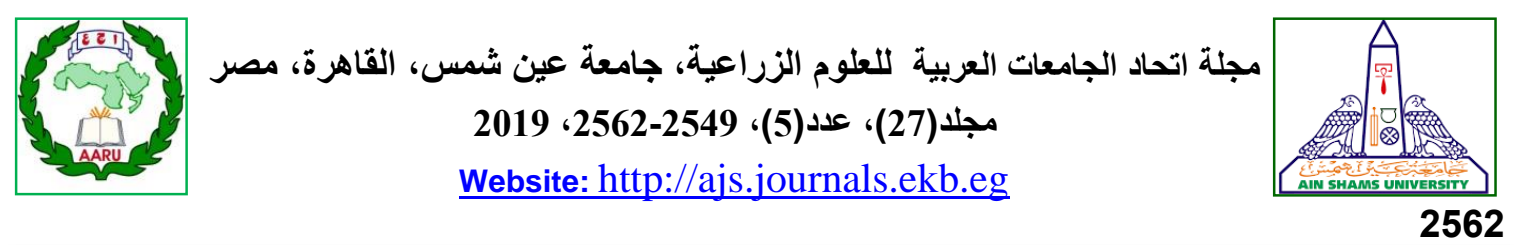

إستخدام بكتيريا حمض اللاكتيك فى تحسين جودة الجبن الطرى المسوى خالى الدسم

[202]

$$
\begin{aligned}
& \text { رشا عبد السلام غباشي1" - محمد عبد الرازق النواوى2 - أحمد محمد حسنين } 1 \text { - إيهاب السيد عمارة2 }
\end{aligned}
$$

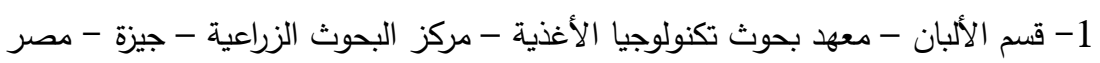

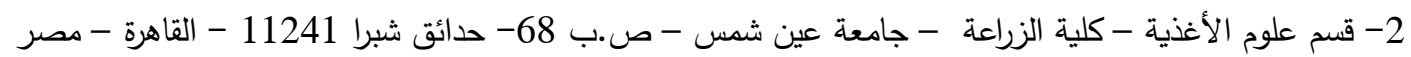

*Corresponding author: Rashaabdelsalam82@yahoo.com

Received 18 November, 2019

Accepted 12 January, 2020

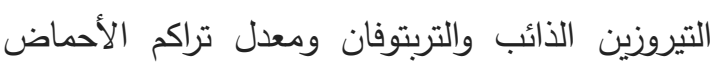

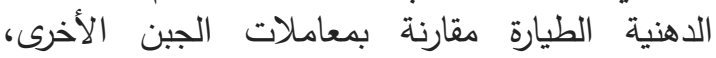

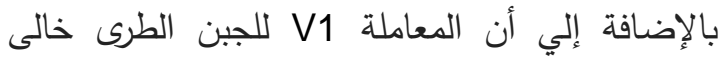

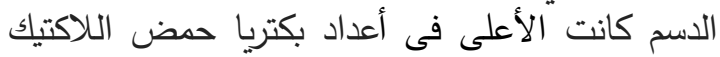
سواء كانت طازجة او خلال فترة التخزين.

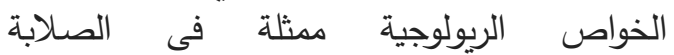
والمضغية Chewiness Hardness adhesiveness والالتصاق cohesiveness والصمغية gumminess كانت أعلى فى الجبن كامل

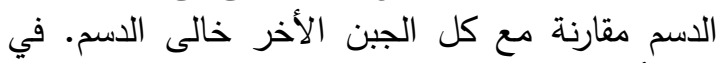

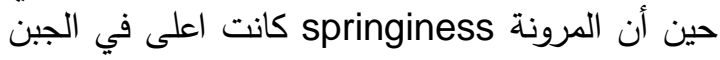

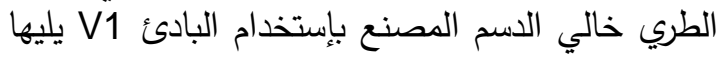

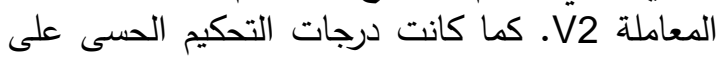

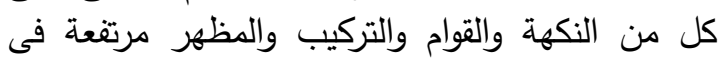

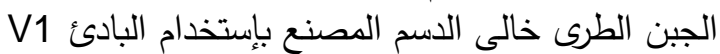

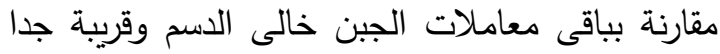

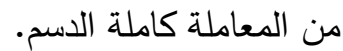
وبالتالى يمكن التوصية باستخدام البادئ V1 الذئي

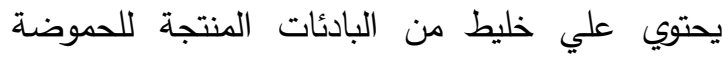
YF-) والبادئات المنتجة للسكريدات العدئية (A1)

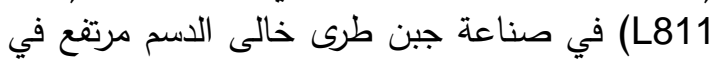
الصفات الكيميائية والميكروبيولوجية والرينية طيولوجية وذو في

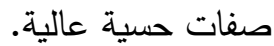

الكلمات الدالة: جبن طري خالي الدسم، بكتريا حمض المضاك

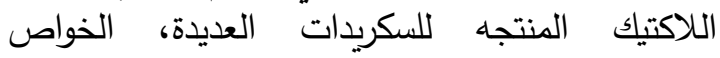

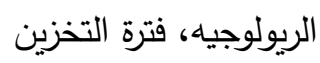

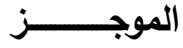

تم تصنيع جبن طرى خالي الدسم من لبن جاموسي

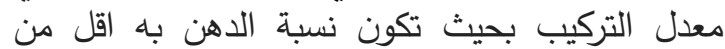
0.05\%، بينما تم تصنيع الجبن المقارنة بإستخدام

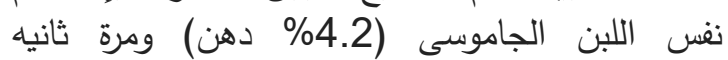
بإستخدام نفس اللبن الجاموسي منزوع الأسم.

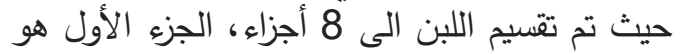
معاملة مقارنة كاملة الدسم وبدون بادئ بين الجزاء الجزي الاول هزي

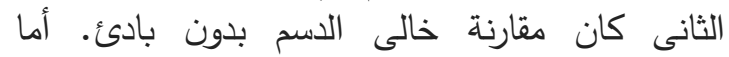

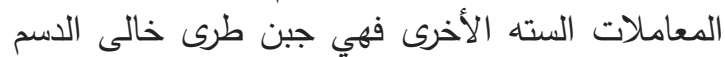

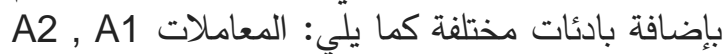
كان بإستخدام بإن V2 بادئات منتجة للحموضة) والمعاملات Daily 42

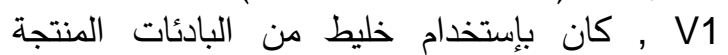
للحموضة (A1) والبادئات المنتجة للسكريدات العديدة

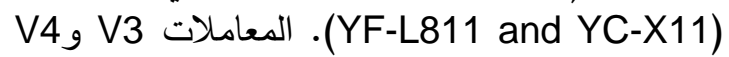
وتصنع من خليط البادئات المنتجة للحموضة (A2)

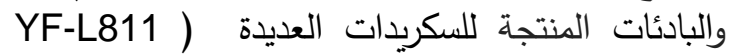
. ( and YC-X11 تم تصنيع ثلاثة مكررات من الجبن الطرى الكامل والخالى الدسم بالطريقة التقليدية ثم تخزينها على التى

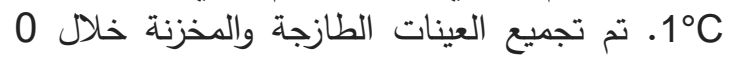

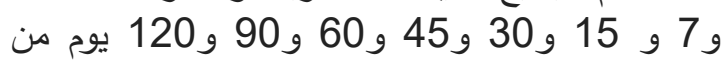

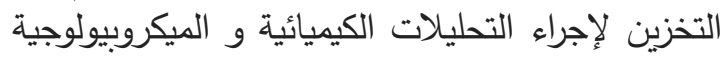

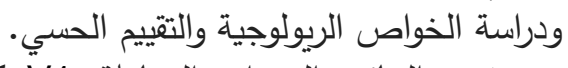

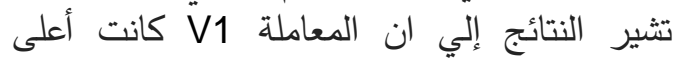

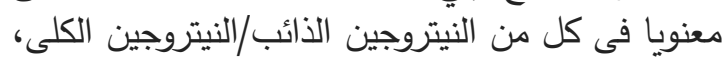

